\title{
Management Priorities In San Andres Island Beaches, Colombia: Associated Risks
}

Portz, Luana Carla; Portantiolo Manzolli, Rogerio; Garzon, Nubia.

\begin{abstract}
San Andres is a touristic island located in the Seaflower Biosphere Reserve, Colombian Caribbean. The island reflects the current territorial dynamics, and economic development. These create significant changes that have been affecting its natural characteristics. The present study analyses the evolution of the landscape characteristics and beach litter situation at 17 points (sandy beaches/rocky shores). The amount and source of waste are different between the tourist beaches (excellent), non-tourist beaches (poor), and rocky shores (good), and correspond to human activities related to beach use and irregular disposal. Solid waste can be observed on trails, footbridges, vacant lots, and especially on non-tourist beaches. Beaches located farthest away from the island's touristic center are the most affected by litter, which puts tourists seeking beaches with a lower tourist density and local people at risk. These non-tourist beaches are considered improper due to the amount of hazardous solid waste present, including glass, even though they have coastal scenario values that are similar to the popular tourist beaches. The environmental management of the island should prioritize all the island beaches considering the fact that environmental quality reflects the growing social and environmental concerns of tourists when choosing their destinations.
\end{abstract}

\section{Keywords}

Beach Users; Coastal Management; Preferences; Tourism. 